\title{
Multiplication in vitro d'artichaut (Cynara scolymus L.) à partir de semences : comparaison au champ de quelques clones à la lignée dont ils sont issus
}

\author{
Claude BIGOT \& Claude FOURY (*) \\ avec la collaboration technique de Monique Casenave, Eric Delacroix, Claudie Delage, Béatrice Godin, \\ Noël Jego \& Jean LEBOEUF \\ Service de Physiologie végétale et (*) Chaire de productions légumières E.N.S.H., 4, rue Hardy, \\ F 78009 Versailles Cedex
}

Un clonage in vitro a été entrepris à partir de plantules d'artichaut (Cynara scolymus L.) appartenant à plusieurs lignées. Les critères de sélection pour le choix des individus è l'origine des souches ont été la précocité et la vigueur de la germination in vitro.

Sur un milieu préalablement établi (BENOIT \& DUCREUX, 1981), le coefficient de multiplication pour le clone le plus prolifique a été de 2,5 pousses axillaires nouvelles toutes les 3 semaines, soit théoriquement $9 \times 10^{5}$ pousses dans l'année ; l'enracinement a été obtenu en présence de charbon actif $(2 \mathrm{~g} / \mathrm{l})$ et d'acide naphtalèneacétique $(0,1 \mathrm{mg} / \mathrm{l})$ : il dépend de la vigueur initiale de la pousse. Après acclimatation en vermiculite à $20^{\circ} \mathrm{C}$, les plantes ont été vernalisées puis installées au champ pour une comparaison avec la lignée dont elles sont issues. L'une d'entre elles (RERI 1-1 $\oplus$ ), plus particulièrement étudiée, a été à l'origine de 4 clones dont l'un seulement s'est révélé au moins égal quant à la valeur agronomique (croissance, forme et couleur des capitules, précocité, productivité). Une bonne homogénéité a été notée à l'intérieur de chaque clone.

Les variations observées se sont montrées comparables à celles des lignées quant à leur type, mais l'une d'entre elles a été amplifiée dans sa fréquence.

L'hétérogénéité entre les clones indique par contre que les 2 prédicteurs choisis, précocité de germination et vigueur des plantules in vitro, ne sauraient être utilisés sans risque dans le but d'une multiplication accélérée à partir de semences issues de lignées peu consanguines ; en effet, ils ne préjugent en rien de la valeur agronomique globale des clones ainsi constitués ou de l'aspect des capitules. L'intérêt du procédé s'en trouve donc amoindri.

Mots clés additionnels : Multiplication in vitro, plantules, acclimatation, production en champ, conformité des plantes.

Cloning in vitro was initiated from seedlings of globe artichoke (Cynara scolymus $\mathbf{L}$.) issued from several lines. The vigour and precocity of germination in vitro were markers for plantlet selection at the beginning of culture. With basic medium (BENOIT \& DUCREUX, 1981), the multiplication coefficient was 2.5 axillary buds every 3 weeks for the most active clone, i.e. $9.10^{5}$ shoots in a year theoretically. Rooting was obtained with active charcoal $(2 \mathrm{~g} / \mathrm{l})$ and naphtaleneacetic acid $(0.1 \mathrm{mg} / \mathrm{l})$ : it depends on the vigour of the shoot. After acclimatization in vermiculite $\left(20^{\circ} \mathrm{C}\right)$, plants were vernalized and put in the field for a comparison with their original lines (growth, form and color of the heads, precocity and yield). Of 4 clones extracted from one of these lines (RERI 1-1 $\oplus$ ), only one has given better results than its mother line, but the intraclonal homogeneity was acceptable for each clone.

The types of morphogenetic variation were similar to those of the lines, but one of them showed a larger frequency than normal.

The observed heterogeneity between clones showed, however, the risk of using vigour and precocity of germination as markers for starting a rapid vegetative propagation programme in vitro from selected seedlings lines of globe artichoke.

Additional key words : In vitro propagation, seedlings, acclimatization, field production, plant conformity. 


\section{INTRODUCTION}

L'artichaut (Cynara scolymus L.) se propage dans la nature à la fois par multiplication végétative et par reproduction sexuée. Les 2 modes ont été pratiqués par l'homme jusque vers la moitié du XVII siècle. Depuis, seul le premier reste utilisé (Foury, 1979a). Les méristèmes axillaires peuvent commencer à croître à partir de la souche après l'induction florale, mais surtout après la récolte, en conséquence directe de la levée de dominance apicale. Malheureusement, la vigueur des pousses axillaires et leur aptitude à l'enracinement varient beaucoup, si bien que le taux de multiplication est généralement faible, de l'ordre de 5 à 6 , et l'hétérogénéité au champ reste importante malgré les soins culturaux. D'autre part, une longue pratique de la multiplication végétative a provoqué, chez cette espèce, une infestation à un taux élevé, soit par des bactéries vasculaires, saprophytiques ou pathogènes, soit par des virus provoquant une dégénérescence, particulièrement sensible dans les pays méditerranéens.

On a tenté l'éradication de ces parasites par la voie de la culture de méristèmes (PENA-IGLESIAS \& AYUSO, 1974, HARBAOUI, 1982 ; PÉCAUT et al., 1983) avant la multiplication végétative in vitro à partir de souches ainsi assainies (DE LEO \& GRECO, 1976 ; HARBAOUI \& DEBERGH, 1980 ; DEBERGH et al., 1981 ; MONCOUSIN, 1981, 1982). Cette manipulation s'est avérée peu aisée : oxydation rapide des explants provoquée par des polyphénoloxydases abondantes, croissance lente, taux élevé d'hyperhydrie, difficultés d'enracinement. Cependant, des améliorations non négligeables ont été récemment apportées par l'ajout de tyrosine à raison de 50 à $100 \mathrm{mg} / \mathrm{l}$ de milieu de culture (MONCOUSIN, 1982). Le semis, outre des qualités génétiques et d'éventuelles simplifications de culture, peut concourir à l'amélioration de l'état sanitaire. Dans ce triple but, une sélection a été entreprise depuis une quinzaine d'années et a abouti à la création de lignées de bonne qualité agronomique (FOURY, $1979 b$; PÉCAUT et al., 1979). Toutefois, la production de semences est limitée par la faible fertilité des lignées sélectionnées à ce jour et l'extrême sensibilité aux aléas climatiques ; celle des $F_{1}$ se heurte de plus à l'absence de stérilité mâle.

Dans ces conditions, il était tentant d'allier les qualités des 2 méthodes, en limitant les défauts, par multiplication in vitro de clones issus chacun d'une semence extraite d'une lignée ou d'une $F_{1}$. Pour vérifier l'intérêt de la méthode projetée, il était nécessaire de décrire successivement les effets :

- de l'état juvénile sur l'activité organogène in vitro et sur la facilité de passage des plantes en plein air,

- de la culture in vitro sur la stabilité des caractères, l'état sanitaire et les performances agronomiques,

- de l'échantillonnage sur l'homogénéité et la conformité des plantes.

Rappelons qu'il est absolument nécessaire de montrer, avant de préconiser une méthode de multiplication in vitro, que l"effet de régulateurs de croissance de synthèse appliqués au cours de cycles successifs de repiquages n'accrô̂t pas, par un biais physiologique, la variabilité naturelle du matériel envisagé et n'intervient pas sur les performances au champ.

Seul l'état sanitaire n'a pas été contrôlé au cours de notre expérimentation.

\section{MATÉRIELS ET MÉTHODES}

L'obtention de plantules à partir de cultures in vitro, leur acclimatation puis leur installation en conditions favorables à la vernalisation, enfin la culture au champ jusqu'à la production, ont nécessité 2 ans d'expérimentation.

\section{A. Matériel végétal}

Les semences sont tirées de 3 lignées $\mathrm{I}_{3}$ ou assimilées : RERI 1-1 $\oplus$ issue de " Romanesco ", VA 2-4 $\oplus$ issue de "Violet de Provence ", CAVO 1-2 $\oplus$, croisement "Camus de Bretagne " $\times$ " Violet de Provence " autofécondé 2 fois. Celles-ci sont assez bien connues car elles constituent le matériel de base du $1^{\text {er }}$ cycle de sélection et des recherches sur la morphogenèse et le développement conduites à Avignon-Montfavet. Quatre clones $C_{1}$ à $C_{4}$ ont été isolés de la lignée RERI 1$1 \oplus$ : ils ont fait l'objet des comparaisons au champ rapportées ci-dessous. En outre, un certain nombre de plantes ont été obtenues à partir de VA 2-4 $\oplus$ et CAVO 1-2 $\oplus$ en culture in vitro et observés en plein air.

\section{B. Culture in vitro et élevage}

\section{Préparation des akènes}

Après imbibition pendant $24 \mathrm{~h}$ dans de l'eau distillée stérile en présence d'un mouillant (Teepol), les akènes ont été désinfectés par un passage dans l'alcool à $70^{\circ}$ pendant $30 \mathrm{mn}$, suivi d'un trempage dans l'hypochlorite de calcium filtré à $100 \mathrm{~g} / \mathrm{l}$ pendant $10 \mathrm{mn}$ et de 3 rinçages de $10 \mathrm{mn}$ chacun dans l'eau distillée stérile. Les embryons ont été alors extraits puis semés en boîte de Petri sur milieu minéral de Murashige \& SKoog, en présence de saccharose $(30 \mathrm{~g} / \mathrm{l})$.

\section{Elevage des embryons et multiplication}

Le but n'étant pas la recherche d'un milieu original, nous avons adopté les méthodes déjà utilisées par BENOIT \& DUCREUX (1981). Au stade cotylédons étalés, les plantules sont installées sur le milieu complet de MURASHIGE \& SKOOG enrichi en phosphate monosodique : $50 \mathrm{mg} / \mathrm{l}$, sulfate d'adénine : $40 \mathrm{mg} / 1$, kinétine : $1 \mathrm{mg} / 1$, acide naphtalèneacétique : $0,1 \mathrm{mg} / 1$, saccharose : $30 \mathrm{~g} / \mathrm{l}$, gélose Bacto agar Difco: $7 \mathrm{~g} / \mathrm{l}$. Le milieu est ajusté à pH 5,5 et autoclavé à $110^{\circ} \mathrm{C}$ pendant $20 \mathrm{mn}$ sous pression. Les tubes de culture sont obturés par des bouchons de cellulose non scellés. Les cultures sont maintenues à $22{ }^{\circ} \mathrm{C}$ de nuit et $25^{\circ} \mathrm{C}$ de jour, sous une intensité lumineuse d'environ 4000 lux dispensée par des tubes fluorescents : Sylvania Gro-lux 40 W, Philips TL $40 \mathrm{~W}$ de luxe, True-Lite Duro-Test $40 \mathrm{~W}$, en mélange, pendant $16 \mathrm{~h}$. Ces conditions sont maintenues constantes durant toute l'expérience.

\section{Enracinement, acclimatation et élevage}

L'enracinement des pousses est pratiqué sur milieu de Murashige \& SKOOG dilué au demi pour les macroéléments, en présence de charbon actif : $2 \mathrm{~g} / 1$ (Merck réf. 2186) et d'acide naphtalèneacétique à la concentration de $0,1 \mathrm{mg} / \mathrm{l}$. 
L'acclimatation des pousses enracinées s'effectue en serre, à $20{ }^{\circ} \mathrm{C}$ et en jours de $16 \mathrm{~h}$, un complément d'éclairage artificiel de 4000 lux environ, n'excédant pas $6 \mathrm{~h}$, est donné par des lampes Phytoclaude à décharge de $400 \mathrm{~W}$. Le substrat constitué de vermiculite est imbibé d'une solution nutritive de type CoÏC \& LESAINT (1975) diluée au demi.

Les akènes RERI 1-1 $\oplus$, destinés à constituer le lot témoin semis, ont été mis en germination début juin, à peu près simultanément avec le $2^{\mathrm{e}}$ repiquage des $5^{\mathrm{e}}$ et $6^{\mathrm{e}}$ subcultures du clone $C_{3}$ de cette lignée mise en comparaison.

Les 2 lots ont été élevés pendant 9 mois en conteneurs de 21 de substrat riche en terre franche. Placés en serre froide, ils ont subi des températures basses mais positives durant tout l'hiver, c'est-à-dire que la vernalisation s'est exercée longuement sur des plantes assez âgées ayant émis plus de 20 feuilles. D'après des expériences antérieures, nous pensons avoir ainsi réduit au mieux les différences de développement, sources essentielles des difficultés de comparaison entre lignées et clones.

$\mathrm{Au}$ cours de ces différentes étapes, des observations et mesures individuelles relatives à la vigueur, l'aspect morphologique et l'enracinement ont été effectuées.

\section{Culture au champ}

Toutes les plantes ont été sorties et mises en place le 17 mars 1982.

\section{Dispositif sur le terrain}

Trente couples lignée/clone $\mathrm{C}_{3}$ de chacun une plante ont été répartis en 6 lignes ; un tel effectif permet généralement de bien différencier les lignées, voire les clones.

Les plantes des clones $\mathrm{C}_{1}, \mathrm{C}_{2}, \mathrm{C}_{4}$ et de ceux issus de CAVO 1-2 $\oplus$ et VA 2-4 $\oplus$ ont été disposées à la suite les unes des autres en lignes successives.

\section{Mesures et observations}

Les anomalies et les caractères subjectifs tels que couleur, forme, ont été observés individuellement à plusieurs reprises sur toutes les origines.

Sur chaque plante des semis de RERI 1-1 $\oplus$ et du clone $C_{3}$, nous avons apprécié les 11 caractères suivants : durée du cycle du repiquage en conteneur à la $1^{\text {re }}$ récolte, nombre de feuilles formées pendant ce temps, nombre de capitules, poids des capitules de $1^{\text {er }}$ et d'ordre supérieur, poids total, rapport longueur/largeur du capitule de $1^{\text {er }}$ ordre, durée de la récolte, hauteur de l'axe principal du groupement d'inflorescences, nombre de bourgeons axillaires en croissance les 11 et 29 août. Les moyennes des distributions et le rapport de leurs variances caractérisant la dispersion des mesures sont comparées par le test $\mathrm{F}$, l'analyse par couple n'ayant pu être faite par suite de différents incidents. La signification est établie au seuil 5 p. 100. La comparaison des régressions des poids et dimensions de l'inflorescence généralement indispensable (FOURY, 1969) s'est révélée inutile compte tenu des faibles différences d'âge des capitules et de leur égale rapidité de vieillissement.

\section{RÉSULTATS}

\section{A. Manipulations in vitro}

\section{Multiplication végétative à partir de plantules}

\section{a) Cas de la lignée RERI 1-1 $\oplus$}

Quatre plantules ont été retenues pour initier la multiplication. Elles correspondent aux embryons isolés dont l'activité de croissance a été la plus précoce. Elles sont à la base de la constitution de 4 clones notés $C_{1}$ à $\mathrm{C}_{4}$.

Le $1^{\text {er }}$ repiquage des plantules s'est effectué après la production de la $4^{\mathrm{e}}$ feuille afin d'atteindre une vigueur de souche suffisante (fig. 1).

De façon à affaiblir les compétitions nutritionnelles s'établissant entre les feuilles en voie de croissance et leurs axillaires, celles-ci sont sectionnées au $2 / 3$ à chaque repiquage. Cette technique a permis de stimuler notablement le développement des pousses à partir de la souche ; les plus vigoureuses peuvent être prélevées 3 semaines (quelquefois $15 \mathrm{j}$ ) après la mise en culture de la pousse mère (fig. 2 et 3 ).

La $1^{\text {re }}$ conclusion, que l'on peut tirer du tableau 1 , conduit à souligner la différence notable de réactivité

TABLEAU 1

Effectifs comparés des pousses enracinables obtenues in vitro pour les clones $C_{1} \grave{a} C_{4}$ de « RERI 》 après la $\sigma^{e}$ subculture depuis la germination. Plantlet number for rooting after 6 in vitro subcultures in the case of $C_{1}$ to $C_{4}$ clones from " $R E R I$ " line seedlings.

\begin{tabular}{ccccccc}
\hline Rang & $1^{\text {er }}$ repiquage & $2^{\text {e }}$ repiquage & $3^{\text {e }}$ repiquage & $4^{\text {e }}$ repiquage & $5^{\text {e repiquage }}$ & $6^{\text {e repiquage* }}$ \\
\hline Clone $C_{1}$ & 0 & 1 & 2 & 4 & 5 & 8 \\
\hline Clone $C_{2}$ & 0 & 0 & 1 & $2(\times 2)$ & $6(\times 3)$ & $12(\times 2)$ \\
\hline Clone $C_{3}$ & 4 & $13(\times 3,2)$ & $36(\times 2,7)$ & $106(\times 2,9)$ & $137(\times 1,3)$ & $240(\times 2,2)$ \\
\hline Clone $C_{4}$ & 2 & $6(\times 3)$ & $8(\times 1,3)$ & $23(\times 2,8)$ & $81(\times 3,5)$ & $140(\times 1,7)$ \\
\hline Total & 6 & 20 & 47 & 135 & 229 & 400 \\
\hline
\end{tabular}

* soit, 6 mois après la germination des embryons isolés in vitro i.e., 6 months after germination of isolated embryos in vitro. (entre parenthèses, coefficient de multiplication entre 2 repiquages successifs) (in brackets, multiplication coefficient between 2 subcultures). 


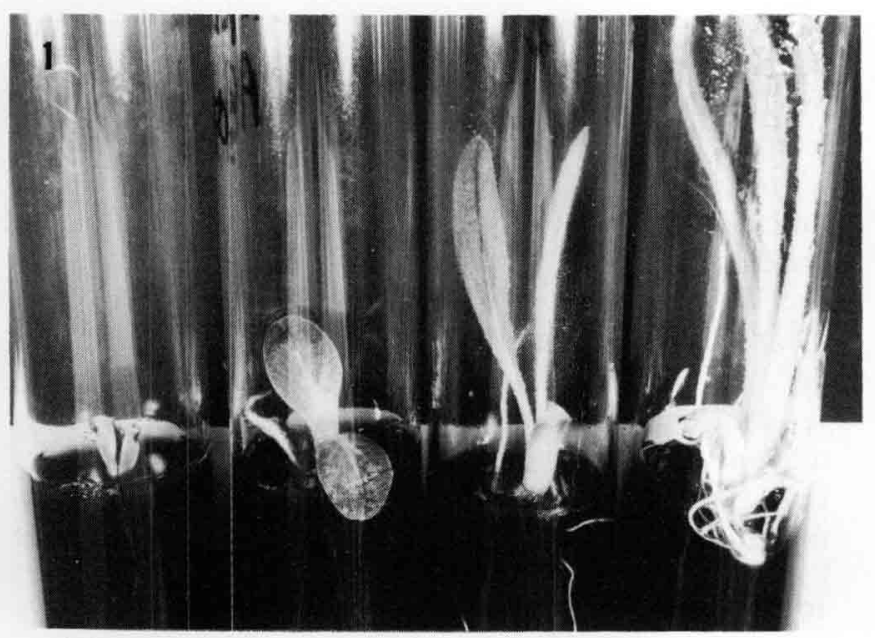

Figure 1

Développement in vitro d'une plantule de « RERI » avant la mise en culture pour clonage.

'RERI' seedling development in vitro before cloning.

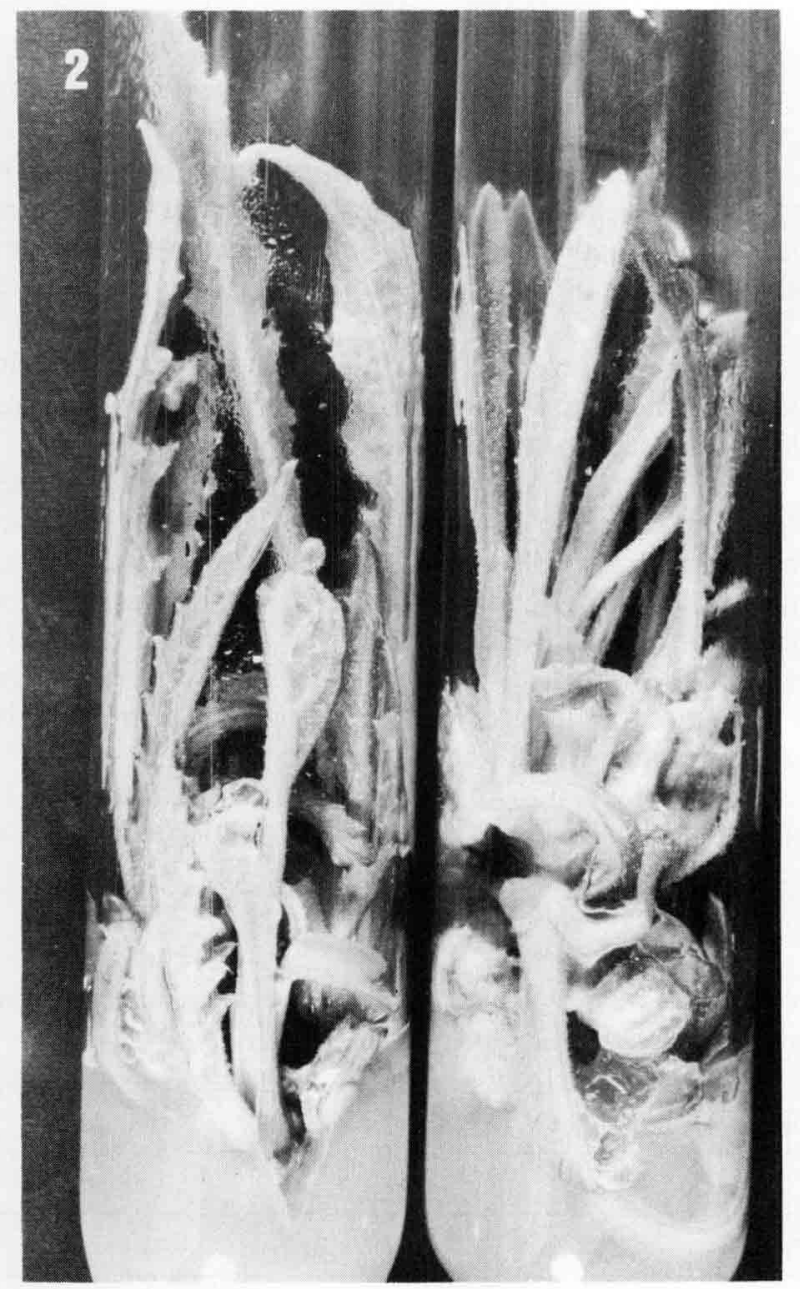

Figure 2

Croissance des méristèmes axillaires sur le milieu de base dans le cas du clone « RERI» $C_{3}$.

Axillary budding in the case of clone 'RERI' $C_{3}$ cultivated on basal medium.

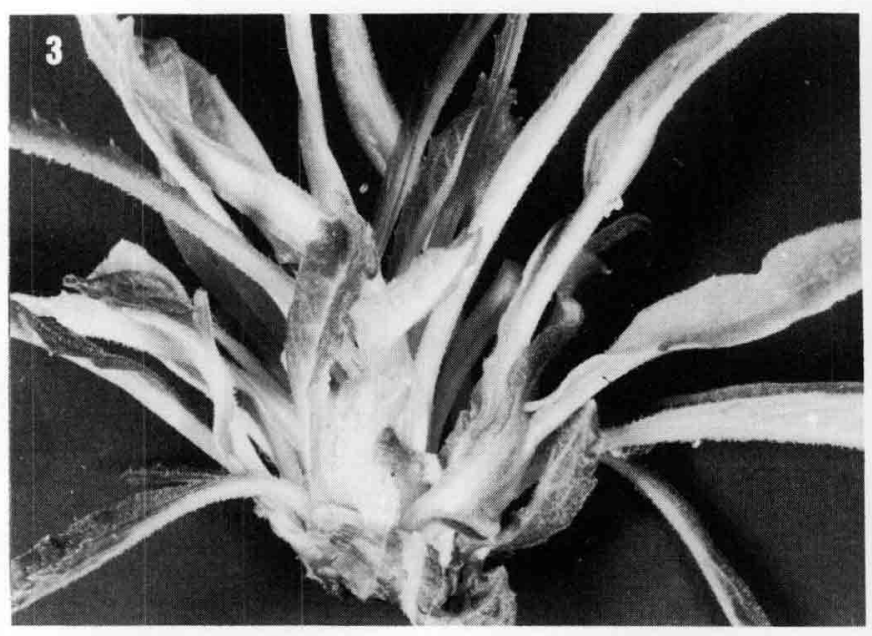

Figure 3

Aspect des méristèmes axillaires avant séparation, 3 semaines après la mise en culture d'une pousse mère sur le milieu de base.

Axillary bud morphology before separation, 3 weeks after subculturing the mother plant.
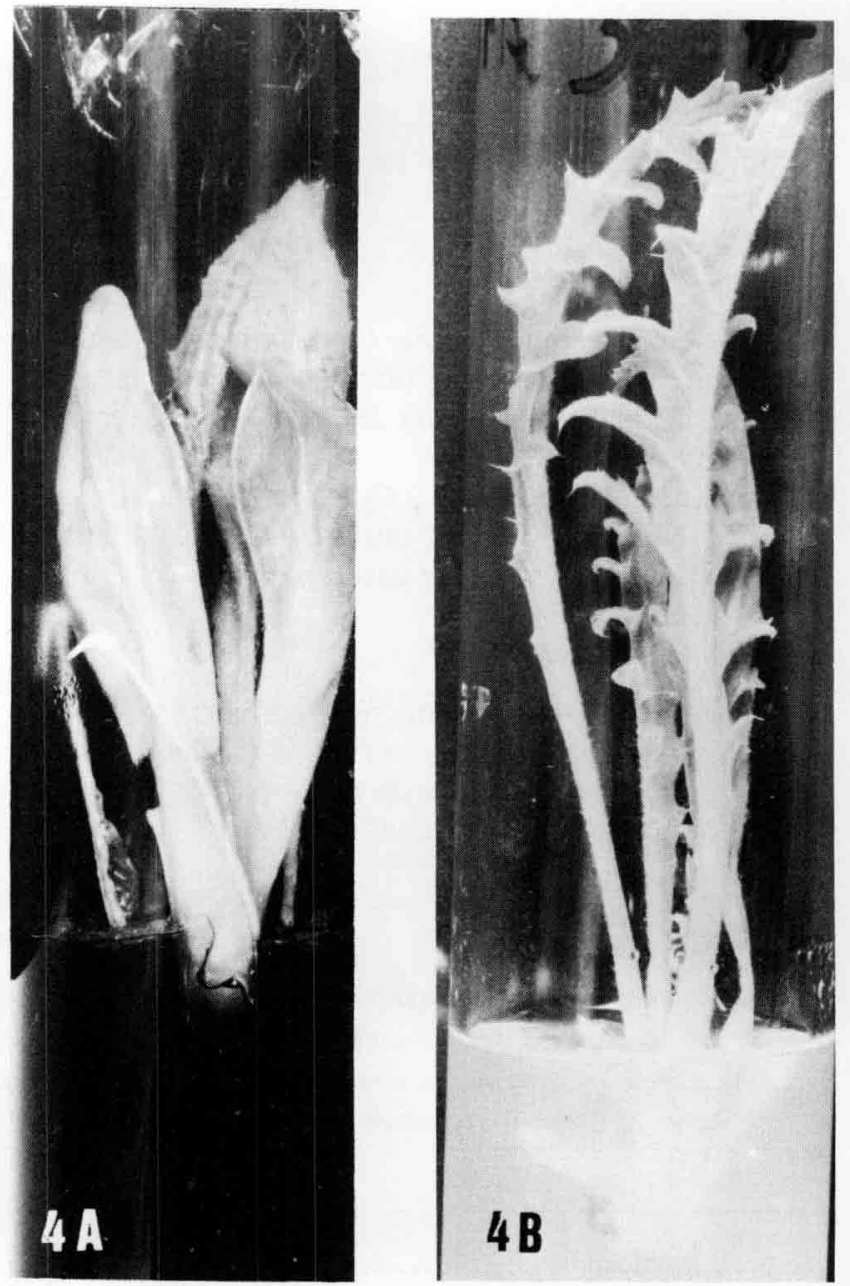

Figure 4

Evolution de la morphologie foliaire de la plantule initiale du clone «RERI $C_{3}$ au fil des repiquages.

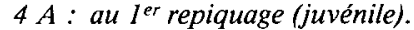

$4 B:$ au 7 repiquage (adulte).

Morphological leaf development of the initial seedling 'RERI' $C_{3}$ : $4 A: 1^{\text {st }}$ subculture (juvenile).

$4 B: 7^{\text {th }}$ subculture (adult). 
en début de culture entre les plantules vis-à-vis du milieu utilisé. Les clones $\mathrm{C}_{3}$ et, à moindre degré, $\mathrm{C}_{4}$ ont été les plus prolifiques. Ils seront à l'origine des sujets étudiés sur le terrain pour l'essentiel.

En pratiquant un repiquage toutes les 3 semaines, le taux de multiplication moyen a été de 2,5 pour $\mathrm{C}_{3}$ (axillaires repiquables), l'intervalle de confiance de la moyenne, calculé au $4^{\mathrm{e}}$ repiquage pour $\mathrm{C}_{3}$ est de $\pm 0,45$ à $t 0,05$. On remarquera toutefois une certaine irrégularité de ce taux au fil des repiquages.

L'effet de vigueur de la pousse mère est particulièrement notable sur le taux de multiplication. Ainsi, dans un sondage pour le même clone $\mathrm{C}_{3}$ :

-14 pousses mères vigoureuses ont produit 55 axillaires repiquables, soit une moyenne de 3,9 par souche (8 plantes possédaient 5 axillaires ou plus) ;

- 27 pousses mères peu vigoureuses ont fourni seulement 56 axillaires repiquables, soit 2 par souche.

Remarquons que la séparation des axillaires à un stade trop précoce entraîne un passage supplémentaire sur le milieu afin d'améliorer la vigueur avant l'enracinement.

Notons encore que la plantule initiale a acquis, après le $4^{\mathrm{e}}$ repiquage, une morphologie de type adulte, à feuille disséquée (fig. $4 a$ et $4 b$ ). Les pousses axillaires évoluent de la même manière ; il arrive même qu'elles soient d'emblée de type adulte. Toutefois, l'acquisition de cet état physiologique ne semble pas influencer le nombre de pousses produites, comme l'indique le résultat suivant pour le clone $\mathrm{C}_{3}$ :

- pousses mères ayant une morphologie de jeunesse (feuilles entières) :

- nombre de pousses mères observées $\quad=67$

- nombre moyen d'axillaires repiquables = $2,97 \pm 0,52$.

- Pousses mères ayant une morphologie adulte (feuilles disséquées) :

- nombre de pousses mères observées $\quad=20$

- nombre moyen d'axillaires repiquables $=$ $2,54 \pm 0,45$

Vis-à-vis du milieu de culture, des expériences ont montré que le sulfate d'adénine pouvait ne pas être indispensable. En effet, jugé sur 12 pousses mères, le nombre moyen d'axillaires a été de 3 sans ce composé par rapport à 2,9 pour le témoin. Toutefois, cet aspect n'a pas été approfondi.

Par contre, le tableau 2 indique que la kinétine est nécessaire à l'entrée en croissance des méristèmes de la souche. Cette cytokinine n'a pu être remplacée par l'isopentenyladénine (IPA). Il n'y a jamais eu, dans ces expériences, de callogenèse, ce qui exclut en principe toute activité de néoformation, donc diminue les risques de variation.

Quant à l'hyperhydrie appelée communément vitrification, elle n'a été observée que très rarement par rapport à ce qui est rapporté par d'autres auteurs.

La multiplication proprement dite n'a pas été poursuivie au-delà d'un effectif de pousses jugé suffisant pour établir une culture en plein champ statistiquement significative.

\section{b) Cas des autres lignées}

Sur le milieu employé, le comportement de VA 2-4 $\oplus$ et de CAVO 1-1 $\oplus$ a été différent. D'une manière générale, les plantes ont eu une croissance réduite et ont acquis presque immédiatement une morphologie de plante adulte à feuilles très pileuses et découpées. Ces caractéristiques se sont maintenues au fil des repiquages pendant un an. La figure 5 indique le nombre de copies obtenues dans l'année à partir des plantules initiales. On note des différences, comme précédemment, moins accentuées toutefois. 269 pousses ont pu être isolées pour VA $2-4 \oplus$.

Il est donc clair que le milieu doit être revu dans sa composition, probablement au niveau des équilibres de régulateurs, pour obtenir une stimulation adéquate dans le cas de chacun des génotypes.

\section{Rhizogenèse in vitro}

\section{a) Clones issus de RERI}

L'acide naphtalèneacétique à la concentration de $0,1 \mathrm{mg} / \mathrm{l}$ s'est montré efficace pour la rhizogenèse adventive, sans entraîner de callogenèse, résultat acquis

TABLEAU 2

Effets de quelques constituants du milieu sur l'organogenèse.

Effects of some medium components on organogenesis.

\begin{tabular}{lcc}
\hline \hline \multicolumn{1}{c}{ Milieu } & $\begin{array}{c}\text { Nombre de tubes } \\
\text { avec axillaires repiquables }\end{array}$ & $\begin{array}{c}\text { Intensité de croissance } \\
\text { de la pousse mère et des axillaires }\end{array}$ \\
\hline Témoin* & $8 / 12$ & +++ \\
\hline Sans phosphate monosodique & $6 / 12$ & 0 \\
\hline Sans régulateur & $0 / 12$ & 0 \\
\hline Sans kinétine & $0 / 12$ & 0 \\
\hline Sans ANA & $8 / 11$ & 0 \\
\hline \begin{tabular}{l} 
Milieu minéral seul \\
\hline ANA (0,1)
\end{tabular} & $0 / 10$ & + \\
IPA (isopentenyladénine) (3) & $0 / 12$ & + \\
\hline \hline
\end{tabular}

* milieu complet décrit dans le chapitre « Matériels et méthodes » basal medium as described in materials and methods. 


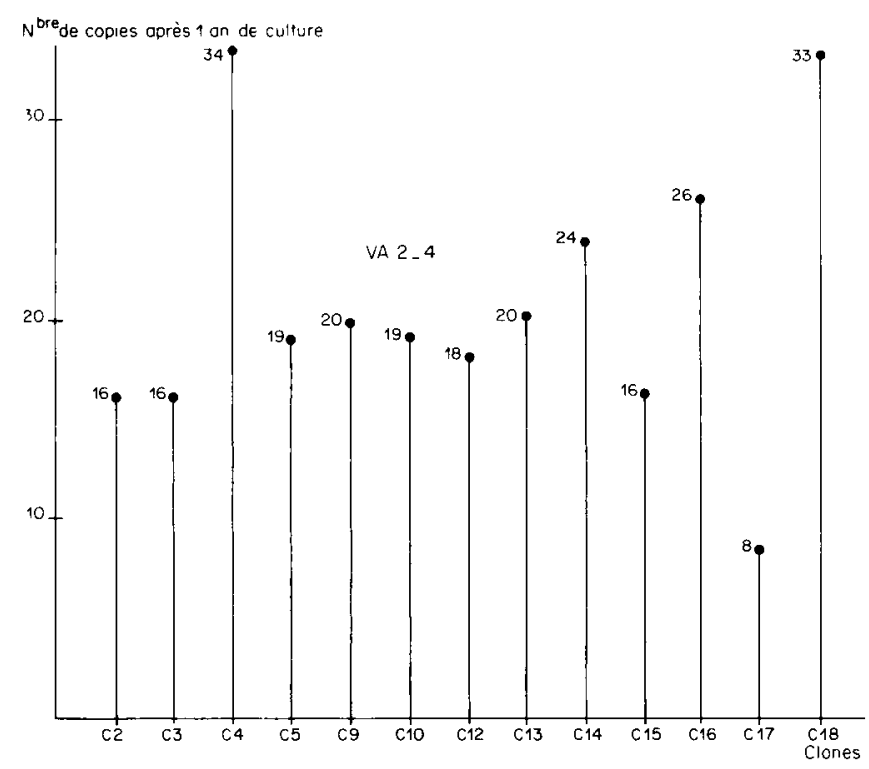

Figure 5

Rendement de la multiplication pour plusieurs clones de VA 2-4, après un an de culture.

Propagation yield for some clones from seedlings of $V A$ 2-4 line, after one year.

après quelques expériences préliminaires faisant intervenir d'autres auxines. Les indications rapportées cidessous correspondent à un effectif de 84 pousses provenant du clone $C_{3}$ :

- Nombre de plantes enracinées après 3 semaines = 57 p. 100.

- Nombre de plantes enracinées après 4 semaines $=$ 67 p. 100.

- Nombre de plantes enracinées après 5 semaines $=$ 77 p. 100.

Après 5 semaines, 23 p. 100 de l'effectif total des pousses n'ont donc produit aucune racine : il s'agissait d'individus faibles pour la moitié ou de pousses à morphologie adulte pour l'autre moitié.

Après 3 semaines, le nombre moyen de racines par plante est de :

$$
2,6 \pm 0,6 \text { (extrêmes : } 1 \text { à 12). }
$$

$\mathrm{Si}$ on répartit les plantes enracinées en classes, on obtient après 5 semaines de culture :
- Plantes ayant 1 à 2 racines $\quad=40$ p. 100

- Plantes ayant 3 à 4 racines $=38$ p. 100 .

- Plantes ayant 5 racines ou plus $=22$ p. 100 .

La vigueur de la pousse est très importante pour l'obtention d'une rhizogenèse active et rapide : ainsi, 40 p. 100 des pousses ayant au moins 5 feuilles se sont enracinées après $15 \mathrm{j}$ et présentaient, après 3 semaines, une moyenne de $3,9 \pm 1$ racines de 5 à $10 \mathrm{~cm}$ de longueur. Ceci est donc au-dessus de la moyenne générale indiquée plus haut. De telles plantes (fig. 6) seront acclimatées en serre sans aucune perte.

Le clone $\mathrm{C}_{4}$ donne les mêmes résultats. Cependant, il a pu être observé sur une expérience que les pousses à morphologie de jeunesse avaient pour ce clone plus d'aptitude à s'enraciner (3,3 racines/plante) que celles ayant atteint le stade adulte (1,3 racine/plante).

\section{b) Autres lignées}

L'enracinement a été beaucoup moins facile par rapport à la lignée RERI et il a été souvent nécessaire, pour l'obtenir, d'effectuer plusieurs passages sur le milieu avec charbon actif et ANA. 21 p. 100 seulement des plantes ont pu être passées en acclimatation. Rappelons que la morphologie adulte est atteinte très rapidement.

\section{B. Acclimatation en serre}

Après enracinement, l'acclimatation s'effectue en 2 ou 3 étapes :

- 1 ou 2 repiquages sur vermiculite dans les conditions rapportées dans le chapitre II :

- puis installation en conteneurs d'attente, la vernalisation s'effectuant en serre avant passage sur le terrain, comme il a déjà été signalé.

Le tableau 3 répertorie l'ensemble des opérations, depuis la sortie de tubes jusqu'à l'installation effective en champ. On constate que le pourcentage global de perte a été de 40 p. 100 , ce qui est assez élevé et doit être imputé :

- à un excès d'humidité pendant le passage en vermiculite (nécrose du collet et asphyxie radiculaire) ;

- à un échauffement exagéré du substrat en cours de séjour en conteneur.

TABLEAU 3

Résultats des acclimatations depuis la sortie de tube jusqu'a l'installation sur le terrain pour les 4 clones issus de germination de « RERI ». Results of acclimatization from test-tube to field for clones from 'RERI' seedlings.

\begin{tabular}{|c|c|c|c|c|c|c|}
\hline Clones & $\mathrm{C}_{1}$ & $\mathrm{C}_{2}$ & $\mathrm{C}_{3}$ & $\mathrm{C}_{4}$ & Total & $\begin{array}{l}\text { Pourcentage } \\
\text { moyen de pertes } \\
\text { entre } 2 \text { étapes }\end{array}$ \\
\hline $\begin{array}{l}\text { Nombre de pousses enracinées } \\
\text { placées sur vermiculite }\left(1^{\text {er }} \text { pas- }\right. \\
\text { sage) }\end{array}$ & 8 & 37 & 305 & 82 & 432 & $21 \%$ \\
\hline $\begin{array}{l}\text { Nombre de pousses placées sur } \\
\text { vermiculite pour un } 2^{e} \text { passage } \\
\text { (vigorisation) }\end{array}$ & 7 & 22 & 253 & 57 & 339 & $15 \%$ \\
\hline Repiquage en conteneurs & 7 & 20 & 212 & 49 & 288 & $10 \%$ \\
\hline Installation sur le terrain & 7 & 16 & 196 & 40 & 259 & \\
\hline
\end{tabular}




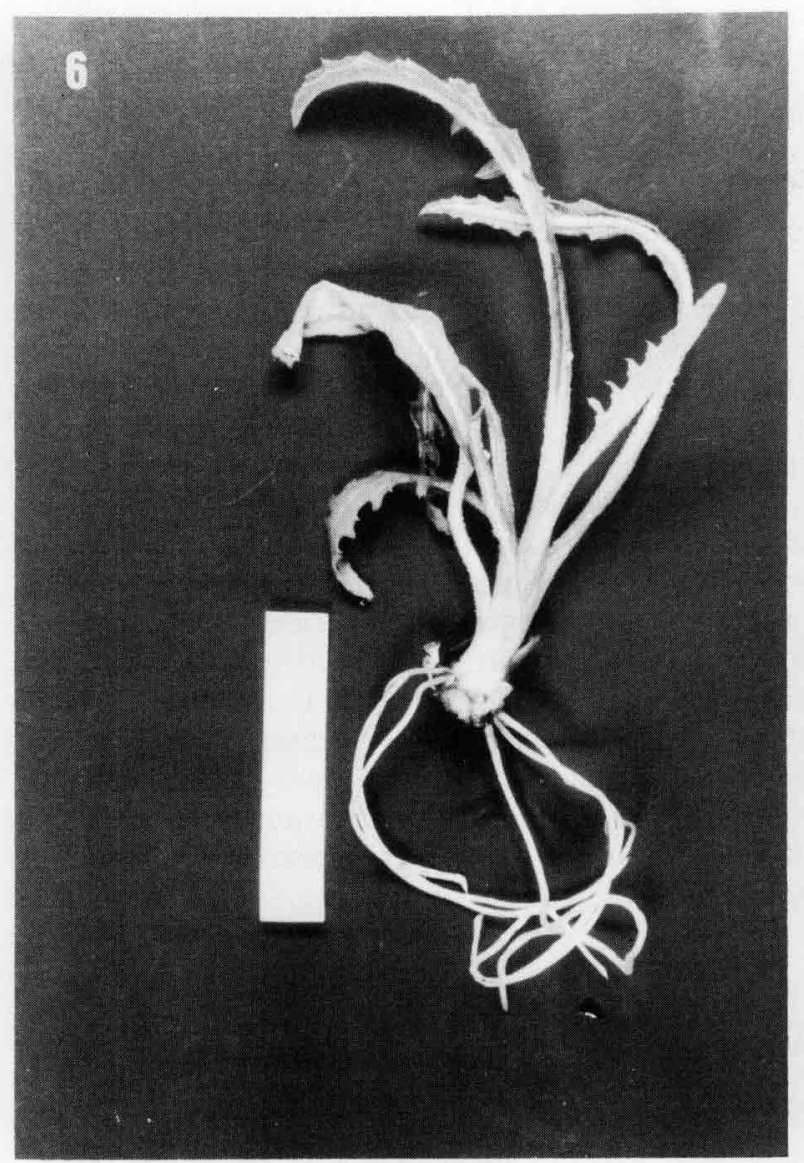

Figure 6

Etat du système racinaire, après 3 semaines de culture, en présence de ANA $0,1 \mathrm{mg} / \mathrm{l}$ (pousses vigoureuses). $\quad$ (index $=5 \mathrm{~cm}$ )

Root developement, after 3 weeks, with NAA $0.1 \mathrm{mg} / \mathrm{l}$ for vigorous shoots.

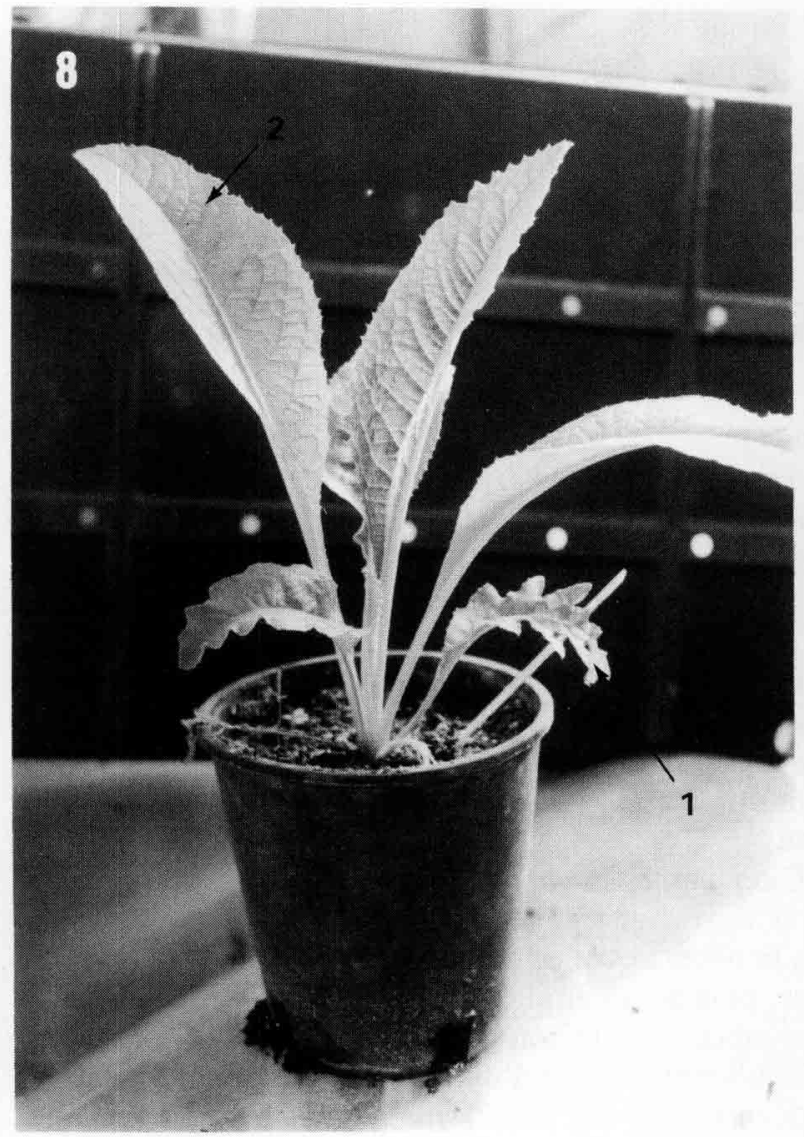

Figure 8

Réversion de l'état adulte (1) vers l'état juvénile (2) pendant la phase d'acclimatation en conteneur.

Adult (1) to juvenile (2) leaf reversion during acclimatization in con-

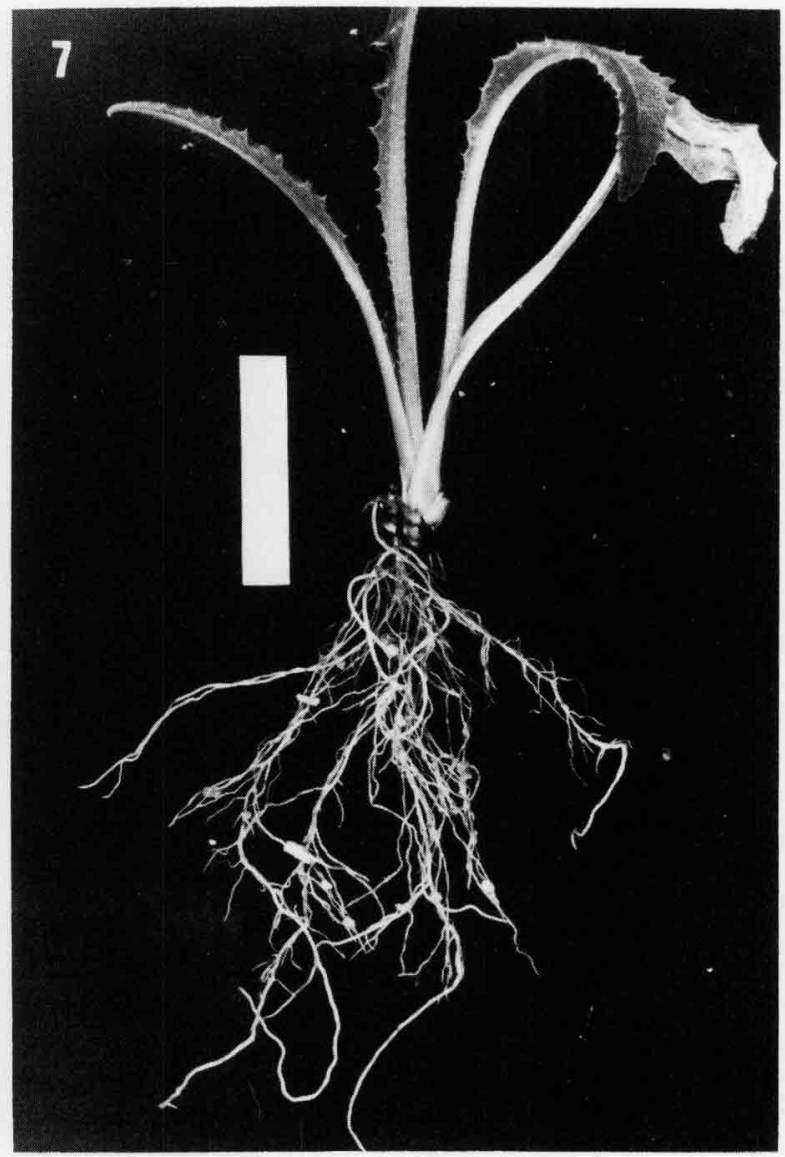

Figure 7

Etat du système racinaire, après acclimatation, pendant $12 \mathrm{j}$ en vermiculite (pousse vigoureuse).

(index $=5 \mathrm{~cm}$ )

Root development, after 12 days of acclimatization in vermiculite.

9

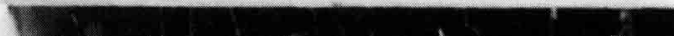

$$
\text { it the }
$$

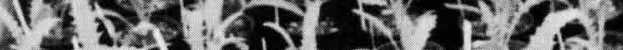

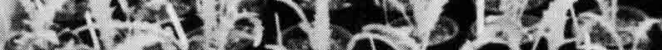

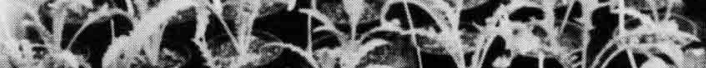

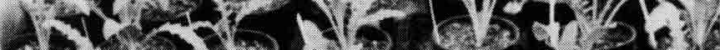

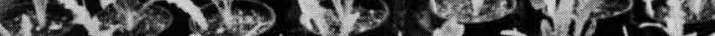

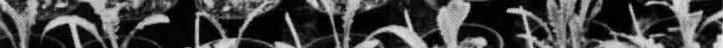

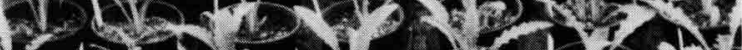

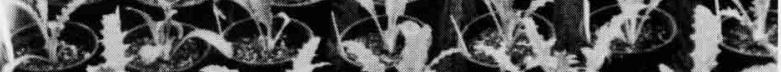

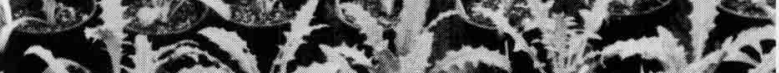

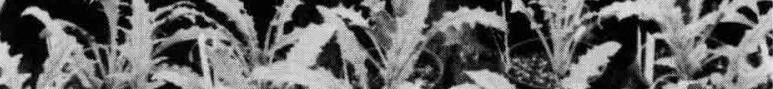

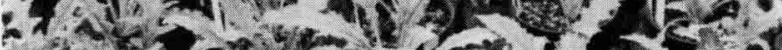
- $11^{5}$ tof A.

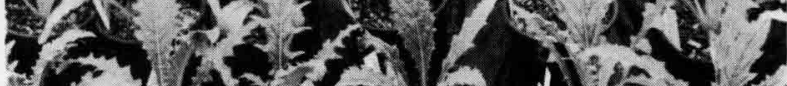

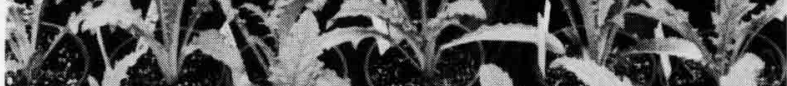

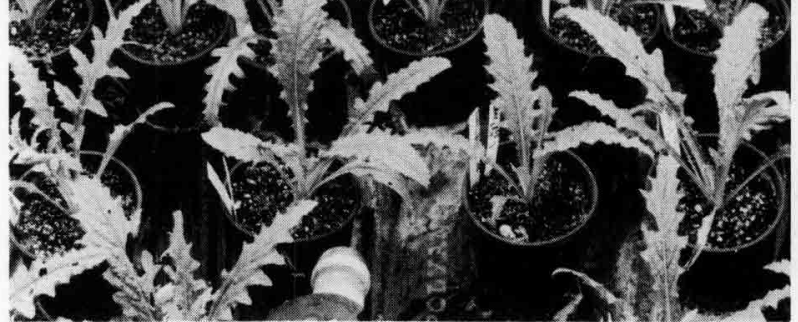

Figure 9

Jeunes plantes en conteneur avant vernalisation.

A set of young plants in container before vernalization. 
La figure 7 montre l'état du système racinaire qui convient bien pour le passage en conteneur. On remarque que le chevelu radiculaire est abondant. Vis-à-vis de l'enracinement, le tableau 4 indique qu'il y a seulement 1 à 2 racines nouvelles émises pendant cette période. L'activité du système racinaire porte donc, pendant l'acclimatation en vermiculite, sur la croissance et la ramification des racines préexistantes.

Notons que 57 p. 100 des plantes (fig. 8) ont reversé vers la forme juvénile, après le passage sur vermiculite.

Les plantes en conteneurs (fig. 9) ont été hivernées en serre froide avant la mise en place, afin de provoquer la vernalisation. On remarquera (tabl. 4) que les axillaires sont apparus très précocement, avant que cette phase du développement ne soit entamée.

\section{TABLEAU 4}

Quelques caractéristiques des plantes acclimatées sur vermiculite avant la transplantation en conteneurs pour 3 clones issus de « RERI».

Some plantlet characteristics after acclimatization on vermiculite before transplantation in containers for 3 clones from 'RERI' seedlings.

\begin{tabular}{lcccc}
\hline \hline \multicolumn{1}{c}{ Clones } & $\mathrm{C}_{2}$ & $\mathrm{C}_{3}$ & $\mathrm{C}_{4}$ & $\begin{array}{c}\text { Total } \\
\text { ou } \\
\text { moyenne }\end{array}$ \\
\hline Nombre de plantes & 7 & 235 & 56 & 298 \\
\hline $\begin{array}{l}\text { Nombre moyen de racines par } \\
\text { plante }\end{array}$ & 3,5 & 4,5 & 3,3 & 3,8 \\
\hline $\begin{array}{l}\text { Nombre moyen de racines rami- } \\
\text { fiées par plante }\end{array}$ & 3,1 & 3,5 & 3,3 & 3,3 \\
\hline $\begin{array}{l}\text { Nombre moyen de pousses axil- } \\
\text { laires visibles par plante }\end{array}$ & 2,2 & 1,6 & 1,4 & 1,7 \\
\hline
\end{tabular}

\section{Comportement au champ}

\section{Vérification de la stabilité des caractères morpho- logiques}

L'observation attentive des plantes et leur référence aux lignées d'origine doivent mettre en évidence l'essentiel des variations discrètes et plus ou moins continues aussi bien que les " mutants ».

En ce qui concerne les premières, il convient de rappeler que les cycles longs, ce qui est le cas ici, permettent la plus large expression des caractères génétiques commandant la forme et la couleur des capitules (FOURY, 1976). Celles-ci sont effectivement beaucoup plus variables pour les semis que pour les 4 clones, $C_{2}$ excepté, qui montrent chacun à la fois une coloration et une forme propres et une grande homogénéité plante à plante. Les bractées sont plus allongées pour le clone $C_{4}$ et plus épineuses pour le clone $C_{3}$. L'effet aurait été, sans doute, plus spectaculaire si de plus nombreux clones avaient été observés. En effet, il se trouve qu'aucun des 4 ne présente le caractère « surcoloré » assez fré- quent dans les descendances du cultivar « Romanesco » (AUBERT \& FOURY, 1979).

La lignée RERI 1-1 $\oplus$ présente environ un tiers des individus fasciés. Leur phyllotaxie est irrégulière des $1^{\text {res }}$ feuilles aux bractées d'involucre ; celles-ci sont déformées et souvent épineuses tandis que les pennes des feuilles sont plus aiguës. Cette "fasciation » s'accompagne fréquemment d'une sensibilité particulière à une bactérie encore non identifiée. Le caractère, sans doute récessif, a été éliminé dans les phases ultérieures de la sélection (FOURY, 1979b). Ici, la descendance autofécondée de RERI 1-1 présente 12 individus fasciés sur 30 mis en place et le clone $C_{2} 18$ plantes sur 18 (fig. 10). Aucune attaque bactérienne n'a été observée. Cette culture a permis de montrer que, contrairement à ce que nous croyions, le caractère se conserve intégralement à travers la multiplication végétative. De même, si les semis fasciés et le clone $C_{2}$ peuvent présenter quelques différences pour des caractères quantitatifs tels que nombre et poids des capitules, leur ressemblance morphologique est frappante.

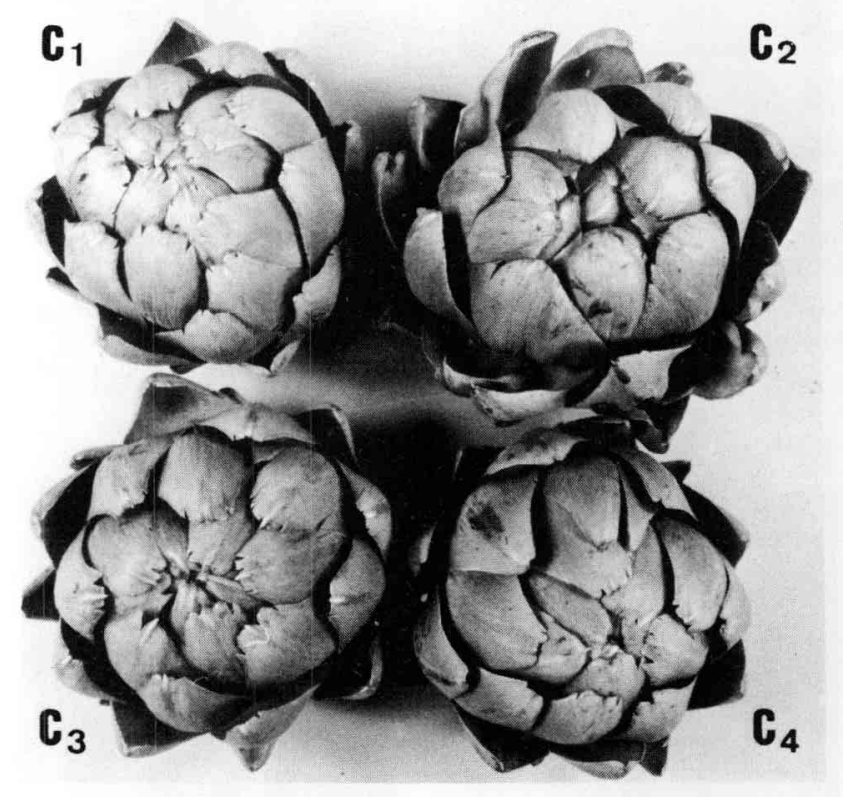

Figure 10

Comparaison de la forme des capitules des 4 clones $C_{1}, C_{2}, C_{3}, C_{4}$. Comparison of head shape in $C_{1}, C_{2}, C_{3}, C_{4}$ clones.

Un clone issu de VA 2-4 $\oplus$ a montré des déformations de bractées un peu semblables; elles sont observées épisodiquement dans cette lignée et il se trouve que la multiplication végétative l'a fixée chez un de ces individus.

Cinq plantes sur 40 du clone $\mathrm{C}_{4}$, soit 12,5 p. 100 , montrent un faciès très particulier (fig. 11) caractérisé par des feuilles à pennes moins nombreuses, moins découpées, plus plates et plus larges ainsi que par un capitule plus aplati en raison de la largeur de ses bractées d'involucre. Il s'agit d'un type de variation déjà signalé (POCHARD et al., 1967) mais nous ne croyons pas l'avoir observé parmi des milliers de plantes issues de semis de "Romanesco " ni parmi les quelques centaines d'œilletons utilisés comme porte-graines. 

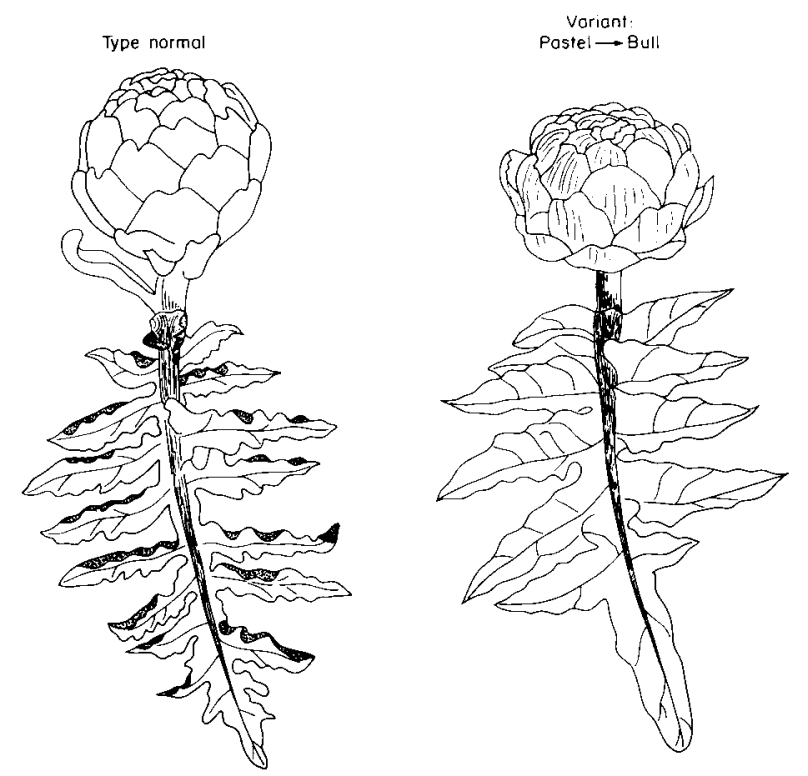

Figure 11

Aspects de capitule de $1^{\text {er }}$ ordre et d'une feuille de rosette de 2 formes du clone $C_{4}$.

Aspect of $1^{\text {st }}$ order capitulum and leaf for 2 forms of $C_{4}$ clone.

\section{Vérification de l'homogénéité et des performances agronomiques}

\section{a) Effet du clonage}

Pour estimer l'effet du clonage dont l'importance est déterminante pour juger la méthode envisagée, nous avons comparé les performances agronomiques, d'une part, du semis RERI 1-1 $\oplus$ et du clone $\mathrm{C}_{3}$, d'autre part, des 4 clones $\mathrm{C}_{1}, \mathrm{C}_{2}, \mathrm{C}_{3}, \mathrm{C}_{4}$.

\section{- Comparaison $C_{3} / R E R I 1-1 \oplus$}

La durée moyenne du cycle, en fait du $1^{\text {er }}$ repiquage à la récolte, est de l'ordre de $385 \mathrm{j}$ et ne varie pas significativement avec le mode de multiplication. Il en est de même pour la période de récolte (tabl. 5).

\section{TABLEAU 5}

Durée du cycle et de la récolte en jours.

Cycle and crop duration in days.

\begin{tabular}{|c|c|c|}
\hline \multirow{2}{*}{ Périodes } & \multicolumn{2}{|c|}{ Durée moyenne en jours } \\
\hline & Semis RERI 1-1 $\oplus$ & Clone $\mathrm{C}_{3}$ \\
\hline $\begin{array}{l}\text { Repiquage en conteneur } / 1^{\text {re }} \text { récolte } \\
1^{\text {re }} / \text { dernière récolte }\end{array}$ & $\begin{array}{r}385,5 \\
24,7\end{array}$ & $\begin{array}{r}384,1 \\
23,8\end{array}$ \\
\hline
\end{tabular}

La vigueur caractérisée par le nombre de feuilles repérées entre la plantation et le stade A (POCHARD, 1961) ainsi que par la longueur de l'axe principal du groupement d'inflorescences est significativement plus forte pour le clone $\mathrm{C}_{3}$ que pour la lignée RERI 1-1 $\oplus$ (tabl. 6).

Le potentiel de multiplication végétative exprimé par le nombre de pousses axillaires émergeant du sol aux 11 et 29 août, soit respectivement 10 et $18 \mathrm{j}$ après la der-
TABLEAU 6

Vigueur comparée selon 2 critères.

Plant vigour comparison between the 2 origins (leaf number/plant; axis height in $\mathrm{cm}$ ).

\begin{tabular}{lcc}
\hline \multirow{2}{*}{ Critères de vigueur } & \multicolumn{2}{c}{ Mode de multiplication } \\
\cline { 2 - 3 } & Semis RERI 1-1 $\oplus$ Clone $\mathrm{C}_{3}$ \\
\hline Nombre de feuilles/plante* & 29,0 & 33,3 \\
Hauteur de l'axe en cm* & 40,9 & 44,2 \\
\hline \hline
\end{tabular}

* Différences des moyennes significatives au seuil 5 p. 100.

nière récolte, ne varie pas significativement avec le mode de multiplication (tabl. 7). Il paraît intéressant d'indiquer, car l'observation n'a jamais été faite, le moindre potentiel des plantes fasciées.

\section{TABLEAU 7}

Potentiel de multiplication végétative.

Comparison of vegetative potential between the 2 origins.

\begin{tabular}{lcc}
\hline \hline \multirow{2}{*}{$\begin{array}{c}\text { Nombre de pousses } \\
\text { axillaires/plante }\end{array}$} & \multicolumn{2}{c}{ Mode de multiplication } \\
\cline { 2 - 3 } & Semis RERI $1-1 \oplus$ & Clone $C_{3}$ \\
\hline le $11 / 8$ & 4,1 & 4,7 \\
le $29 / 8$ & 6,9 & 7,1 \\
\hline \hline
\end{tabular}

Les rendements comme les composantes, nombre et poids des capitules (excepté ceux d'ordres supérieurs) des semis RERI 1-1 $\oplus$ et du clone $\mathrm{C}_{3}$ ne sont pas significativement différents (tabl. 8).

\section{TABLEAU 8}

Rendements et leurs composantes.

Comparison between yield components.

\begin{tabular}{lcr}
\hline \multirow{2}{*}{ Eléments du rendement } & \multicolumn{2}{c}{ Mode de multiplication } \\
\cline { 2 - 3 } & Semis RERI 1-1 $\oplus$ & Clone $\mathrm{C}_{3}$ \\
\hline Nombre capitules/plante & 9,1 & 8,8 \\
Poids en g capitule 1er ordre & 247,0 & 242,0 \\
Poids capitules ordres sup. & 109,0 & 117,0 \\
Rendement g/plante & 1123,0 & 1155,0 \\
\hline \hline
\end{tabular}

* Différences des moyennes significatives au seuil 5 p. 100.

La forme des capitules peut être caractérisée par le rapport hauteur/diamètre qui, en général, diminue avec l'âge. Les capitules de $1^{\text {er }}$ ordre ayant été récoltés à peu près aux mêmes stades, les rapports ont pu être comparés directement ; les valeurs moyennes des clones et des semis sont strictement identiques : 0,91.

- Eléments de comparaison des 4 clones $C_{1}, C_{2}$, $C_{3}, C_{4}$ issus de RERI 1-1 $\oplus$

Pour chacun des caractères mesurés, au moins un des 4 clones diffère des autres (tabl. 9). Le clone $\mathrm{C}_{2}$ fascié se distingue essentiellement par la brièveté de l'axe principal du groupement d'inflorescences. Le clone $\mathrm{C}_{3}$ est à la 
TABLEAU 9

Comparaison des clones $C_{1}, C_{2}, C_{3}$ et $C_{4}{ }^{*}$ issus de la lignée RERI I-I $\oplus$.

Comparison of the characteristics of growth, head and yield for the 4 clones issued from RERI I-I $\oplus$ line.

\begin{tabular}{|c|c|c|c|c|c|c|c|c|c|}
\hline \multirow{2}{*}{ Clones } & \multirow{2}{*}{$\begin{array}{l}\text { Durée cycle } \\
\text { en jours }\end{array}$} & \multirow{2}{*}{$\begin{array}{l}\text { Nombre de } \\
\text { feuilles émises } \\
\text { dans le cycle }\end{array}$} & \multirow{2}{*}{$\begin{array}{l}\text { Longueur axe } \\
\text { inflorescence } \\
\text { en } \mathrm{cm}\end{array}$} & \multicolumn{2}{|c|}{ Poids des capitules } & \multirow{2}{*}{$\begin{array}{l}\text { Nombre de } \\
\text { capitules }\end{array}$} & \multirow{2}{*}{$\begin{array}{l}\text { Production } \\
\text { g/plante }\end{array}$} & \multicolumn{2}{|c|}{ Nombre œilletons/plante } \\
\hline & & & & $1^{\mathrm{er}}$ ordre & Autres ordres & & & le $10 / 8$ & le $29 / 8$ \\
\hline$C_{1}$ & $389 \mathrm{~b}$ & $25,8 \mathrm{c}$ & $43,3 \mathrm{a}$ & $164 \mathrm{c}$ & $89 \mathrm{~b}$ & $5,8 \mathrm{c}$ & $577 \mathrm{~b}$ & $3,3 a b$ & $4,3 \mathrm{c}$ \\
\hline $\mathrm{C}_{28}$ & $389 \mathrm{~b}$ & $29,6 \mathrm{~b}$ & $26,8 \mathrm{c}$ & $202 \mathrm{~b}$ & $77 \mathrm{~b}$ & $6,6 \mathrm{~b}$ & $640 \mathrm{~b}$ & $2,8 \mathrm{~b}$ & $5,6 \mathrm{~b}$ \\
\hline$C_{3}^{4 T}$ & $384 \mathrm{a}$ & 33,3 a & $44,2 \mathrm{a}$ & 242 a & $117 \mathrm{a}$ & $8,8 \mathrm{a}$ & $1155 \mathrm{a}$ & $4,7 \mathrm{a}$ & $7,1 \mathrm{a}$ \\
\hline $\mathrm{C}_{4}^{3}$ & $391 \mathrm{c}$ & $30,6 \mathrm{~b}$ & $37,1 \mathrm{~b}$ & $196 \mathrm{~b}$ & $125 \mathrm{a}$ & $4,6 \mathrm{c}$ & $624 \mathrm{~b}$ & $2,8 \mathrm{~b}$ & $5,3 \mathrm{bc}$ \\
\hline
\end{tabular}

* Les valeurs affectées de la même lettre ne sont pas différentes au seuil de 5 p. 100.

$\mathrm{C}_{2 \mathrm{f}}:$ le clone $\mathrm{C}_{2}$ est fascie.

fois le plus précoce, le plus vigoureux et le plus productif. Il présente le potentiel de multiplication le plus élevé. Il est nécessaire de rappeler, car il s'agit d'un élément important de la discussion, que cette aptitude s'est révélée dès la culture in vitro.

\section{b) Homogénéité intraclonale}

Les variances des distributions du semis de RERI 1-1 $\oplus$ et du clone $C_{3}$ ont été systématiquement comparées pour chacun des 11 caractères étudiés ci-dessus. Elles ne diffèrent jamais significativement au seuil 5 p. 100 , cependant pour 8 caractères la variance de la lignée est supérieure à celle du clone. L'étendue entre les valeurs extrêmes est supérieure pour les semis dans 8 cas sur 11 . Cette variabilité est particulièrement importante, quel que soit le mode de multiplication, pour le nombre d'œilletons : 0 à 10 apparus $10 \mathrm{j}$ après la récolte et pour la production environ 700 à $1560 \mathrm{~g} /$ plante.

Il apparaît donc que la variabilité « d'origine génétique » des principaux caractères agronomiques est relativement faible dès la $\mathrm{I}_{3}$ et du même ordre de grandeur que la variabilité « aléatoire » observée plante à plante sur un clone. Par ailleurs, les variances calculées sur le clone $\mathrm{C}_{3}$ directement issu de multiplication in vitro ne paraissent pas beaucoup plus faibles que celles généralement enregistrées au cours de la sélection clonale du «Violet de Provence ».

\section{DISCUSSION ET CONCLUSION}

L'utilisation de la culture in vitro par l'agronome en vue d'une production nécessite de nombreux contrôles avant la mise en pratique. La preuve doit être faite que la conformité est respectée, l'hétérogénéité réduite, la productivité au moins égale à celle obtenue par voie traditionnelle, l'état sanitaire maintenu sinon amélioré, enfin le coût du procédé non disproportionné vis-à-vis du rapport de la culture.

Dans le cas de $C$. scolymus, la multiplication végétative est limitée par le nombre faible de pousses récoltées annuellement, soit 4 à 7 par plante (FOURY, 1976). En conséquence, il a été étudié depuis plusieurs années une technique de production dont la base serait le semis (FOURY, 1979 : PÉCAUT et al., 1979) ; la sélection de lignées a donc été entreprise pour atteindre cet objectif ; toutefois, diverses difficultés se font jour pour la production de semences : une faible fertilité, un effet d'inbreeding non négligeable, une sensibilité aux conditions climatiques.

La question posée, motivant l'expérimentation rapportée dans cet article, était de rechercher s'il était possible d'exploiter la qualité de lignées éprouvées, dans un programme de multiplication végétative in vitro à partir d'un matériel de base tiré de ces lignées : la plantule. On fait appel ainsi à une qualité physiologique démontrée avec d'autres espèces : la juvénilité, dont l'effet est notable en propagation végétative.

Toutefois, il fallait s'appuyer sur un marqueur pour choisir les individus d'origine menant à la constitution de clones, pour lequel il faudra établir une relation hautement probable avec les caractéristiques agronomiques les plus favorables (forme, couleur des capitules, précocité, productivité...). C'est la vigueur de la germination in vitro que nous avons tenté d'éprouver comme critère de sélection : ce sont donc les $1{ }^{\text {ers }}$ embryons isolés entrés en croissance qui ont été retenus pour initier le processus de multiplication in vitro.

On observera d'abord qu'en présence d'un milieu défini (BENOIT \& DUCREUX, 1981), la réaction organogène dépend des lignées et que le taux de multiplication en début de culture est différent suivant les plantules initiales pour une même lignée (RERI 1-1 $\oplus$ a été étudiée plus précisément). Ce fait avait déjà été rapporté par OHKI et al. (1978) dans le cas de lignées de tomate et de leurs hybrides réciproques et par BIGOT (1983) dans le cas de Pelargonium $\times$ hortorum hybrides $\mathrm{F}_{1}$.

Le clone $\mathrm{C}_{3}$, issu de RERI, a été constitué à partir du $1^{\text {er }}$ embryon germé : il s'est révélé aussi être le plus prolifique très précocement, ce qui appuie notre hypothèse de départ. Le taux de multiplication s'est maintenu à 2,5 pousses toutes les 3 semaines, ce qui est comparable aux résultats rapportés par HARBAOUI (1982) à partir de méristème de «Violet de Provence » ou par MONCOUSIN (1981) dans le cas de plusieurs cultivars (efficacité de multiplication améliorée par ce dernier auteur en 1982 par l'addition de tyrosine dans le milieu de culture). Pour le clone $\mathrm{C}_{3}$, la potentialité théorique est donc de $9 \times 10^{5}$ pousses dans l'année, chiffre bien supérieur à la capacité naturelle d'un individu adulte.

L'effet juvénile s'exprime donc par la rapidité des rotations in vitro, mais se traduit surtout au niveau de la rhizogenèse, ce qui fait encore intervenir la vigueur : en effet, les pousses ayant produit 4 à 6 feuilles visibles s'enracinent facilement en 3 semaines en présence d'auxine (acide naphtalèneacétique $0,1 \mathrm{mg} / \mathrm{l}$ ). En 
revanche, les plantules les plus faibles nécessitent un repiquage supplémentaire afin d'accroître leur vigueur.

Le développement in vitro a été normal : il n'a pas été observé notamment de déviation métabolique conduisant à l'hyperhydrie (appelée communément vitrification), dont l'apparition est liée aux caractéristiques de l'environnement (DEBERGH et al., 1981). Ce résultat est probablement en relation avec les conditions de culture : éclairement de niveau assez élevé (4000 lux) et facilité des échanges gazeux avec l'extérieur, limitant l'accumulation de gaz toxiques comme l'éthylène.

En ce qui concerne la morphogenèse, l'évolution à partir d'un type juvénile (feuilles entières) vers l'état adulte (feuilles découpées) s'effectue irrégulièrement suivant les pousses et les clones au fil des repiquages ; de plus, le retour à l'état juvénile a souvent été observé pendant la phase d'acclimatation, fait rapporté aussi par MONCOUSIN (1981) : on en déduit donc une instabilité du contrôle organogène. Ceci est conforme aux observations de FOURY (1980) qui met en évidence le même phénomène après un arrêt de fonctionnement plastochronique : pour lui, la vitesse d'allongement de l'axe et la longueur du plastochrone (temps séparant l'érection de 2 primordia) constituent 2 facteurs qui modulent la morphologie foliaire dans le cas de l'artichaut.

Quant à la variabilité du comportement des pousses pour un clone donné, il faut signaler une bonne homogénéité des plantes installées au champ, probablement en relation avec l'absence de callogenèse : c'est donc un garant de crédibilité de la méthode. Néanmoins, il est remarquable que 2 anomalies aient pu être mises en lumière in vitro :

- l'une est générale pour le clone $C_{2}$ (issu de RERI) : celui-ci a révélé pour tous les individus le caractère de fasciation présent dans cette lignée et qui affecte en principe $1 / 3$ des plantes ;

- l'autre est beaucoup plus rare : elle correspond à un variant entre 2 types nommés "Pastel» et « Bull » décrits par PoCHARD et al. (1967) dès le début de la sélection clonale du «Violet de Provence». 5 plantes du clone $\mathrm{C}_{4}$ (fig. 11) sont en effet à rapprocher de ce variant: feuilles peu découpées (dont les pennes sont larges) et capitules subsphériques. Sa pré- sence n'introduit donc pas une anomalie nouvelle, mais sa fréquence $(12,5 \mathrm{p} .100)$ est nettement plus élevée que dans la nature ( 1 à 2 p. 100). Ceci implique que son apparition a été probablement très précoce au cours de la culture ; elle est d'autre part incontrôlable, si bien que le risque d'une multiplication à grande échelle se pose d'autant plus que ce variant est considéré comme non commercialisable. Cette modification morphologique serait imputable à un contrôle différent du fonctionnement génétique (NOZERAN \& BANCILHON, 1972 ; NOZERAN, 1978).

Enfin, la comparaison au champ permet de tirer 2 conclusions :

- le clone $\mathrm{C}_{3}$ s'est révélé plutôt supérieur bien que certaines différences ne soient pas significatives ;

- une hétérogénéité des performances entre les 3 clones à capitules normaux est mise en évidence, $C_{1}$ et $\mathrm{C}_{4}$ étant inférieurs à $\mathrm{C}_{3}$ (donc à la lignée d'origine), ceci en excluant $\mathrm{C}_{2}$ qui révèle le caractère de fasciation.

En conclusion, il s'ensuit que la rapidité de germination et la vigueur des plantules ne pourraient constituer 2 prédicteurs efficaces de la puissance de multiplication in vitro de clones isolés à partir de semences. En outre, ils ne préjugent en rien de la valeur agronomique globale et de l'aspect des capitules. On ne peut donc les utiliser sans risque pour choisir des plantules tête de clone parmi des semences en $\mathrm{I}_{2}$ ou $\mathrm{I}_{3}$. L'utilisation pratique de la méthode n'est cependant pas à exclure pour la multiplication de lignées intéressantes et homogènes, mais déprimées par une forte consanguinité, ou d'hybrides $F_{1}$ dont les semences sont difficiles à produire. Toutefois, depuis le début de ce travail, les méthodes de culture et d'élevage à partir de méristèmes de plantes adultes ont suffisamment progressé pour constituer d'autres solutions intéressantes à ce problème.

Reçu le 10 mai 1983. Accepté le 3 avril 1984.

\section{REMERCIEMENTS}

Mademoiselle L. PATourel, Ingénieur E.N.S.H., a réalisé les mises en culture d'embryons. Nous la remercions.

\section{RÉFÉRENCES BIBLIOGRAPHIQUES}

Aubert S., Foury C., 1979. Couleur et pigmentation anthocyanique de l'artichaut (Cynara scolymus L.). In studi sul carciofo. Atti $3^{e}$ Congr. Int. Sul Carciofo. Bari, 57-76.

Benoit H., Ducreux G., 1981. Etude de quelques aspects de la multiplication végétative in vitro de l'artichaut (Cynara scolymus L.). Agronomie, 1 (3), 225-230.

Bigot C., 1983. Multiplication végétative in vitro à partir de plantules d'hybrides $\mathrm{F}_{1}$ de Pelargonium $\times$ hortorum Bailey. Acta Hortic., 131, $61-70$.

Coic Y., Lesaint C., 1975. La nutrition minérale et en eau des plantes en horticulture avancée. Documents techniques de la F.C.P.A., $\mathrm{n}^{\circ} 23,22 \mathrm{p}$

Debergh P., Harbaoui Y., Lemeur R., 1981. Mass propagation of globe artichoke (Cynara scolymus L.) : evaluation of different hypotheses of overcome vitrification with special reference to water potential. Physiol. Plant., 53, 181-187.
De Leo P., Greco B., 1976. Nuova technica di propagazione del Carciofo : Coltura in vitro dei meristemi apicali. $2^{\circ}$ Cong. Int. Sul Carciofo, Bari. Ed. Minerva Medica Torino, 657-665.

Foury C., 1969. Etude de la biologie florale de l'artichaut (Cynara scolymus L.). Application à la sélection. II. Etude des descendances obtenues en fécondation contrôlée. Ann. Amélior. Plant., 19 (1), 23 52.

Foury C., 1976. Recherches sur l'artichaut. C. R. d'activité de la Station d'Amélioration des Plantes Maraîchères, I.N.R.A. AvignonMontfavet, 5-13.

Foury C., 1979a. Intérêt des recherches historiques pour l'explication des techniques culturales. Atti $3^{\circ}$ Cong. Int. Sul Carciofo, Bari, 321333.

Foury C., 1979b. Quelques aspects pratiques de la sélection généalogique de l'artichaut. I. Présentation, création de lignées. Ann. Amélior. Plant., 29, 383-418. 
Foury C., 1980. Etudes sur le développement et la mise à fleur de l'artichaut (Cynara scolymus L.) issu de boutures et de semis. Thèse Doct. Ing., Univ. P. et M. Curie, 162 p.

Harbaoui Y., Debergh P., 1980. Multiplication in vitro de clones sélectionnés d'artichaut (Cynara scolymus L.). In : Application de la culture in vitro à l'amélioration des plantes potagères. Eucarpia, section légumes, Versailles, 1-7.

Harbaoui Y., 1982. Multiplication in vitro et assainissement viral de l'artichaut, Cynara scolymus L. Thèse Doct. Sci. Agron., Rijksuniversiteit Gent, $159 \mathrm{p}$

Moncousin C., 1981. Multiplication végétative accélérée de Cynara scolymus L., Rev. Hort. Suisse, 54, 105-111.

Moncousin C., 1982. Contribution à la caractérisation biochimique et physiologique de la phase juvénile de l'artichaut (Cynara scolymus L.), au cours de la multiplication végétative conforme et accélérée en culture in vitro. Thèse Doct. Ing., Univ. Paris Sud, Orsay, 238 p.

Nozeran R., Bancilhon L., 1972. Les cultures in vitro en tant que technique pour l'approche de problèmes posés par l'amélioration des plantes. Ann. Amélior. Plant., 22, 167-185.

Nozeran R., 1978. Polymorphisme des individus issus de la multipli- cation des végétaux supérieurs avec conservation du potentiel génétique. Physiol. Vég., 16, 177-194.

Ohki S., Bigot C., Mousseau J., 1978. Analysis of shoot forming capacity in vitro in two lines of tomato (Lycopersicum esculentum Mill.) and their hybrids. Plant and Cell Physiol., 19, 27-42.

Pecaut P., Foury C., Rico F., Martin F., 1979. Bilan d'un premier cycle de sélection de variétés d'artichaut à semer. $3^{\circ}$ Cong. Int. Sul Carciofo, Bari, Industria Grafica Laterza, Bari, 615-627.

Pecaut P., Dumas de Vaulx R., Lot H., 1983. Virus-free clones of globe artichoke (Cynara scolymus L.) obtained after in vitro propagation. $21^{\circ}$ Congrès Int. Hort. Hambourg. 29 août-4 septembre 1982. Acta Horticulturae, 131, 303-309.

Pena-Iglesias A., Ayuso P., 1974. The elimination of viruses from globe artichoke (Cynara scolymus L.) by etiolated meristem culture. Proc. XIX Int. Hort. Cong., Warszawa, 1 A, 63.

Pochard E., 1961. Les stades phénologiques de l'artichaut. In $C . R$. d'Activité de la Station d'Amélioration des Plantes I.N.R.A. Avignon-Montfavet, 37-48.

Pochard E., Foury C., Chambonnet D., 1967. Il miglioramento genetico del carciofo. Atti $1^{\circ}$ Cong. Int. Sul Carciofo, Bari, 117-143. 